\title{
CLINICAL RELEVANCE OF CHEK2 AND NBN MUTATIONS IN THE MACEDONIAN POPULATION
}

\author{
Maleva Kostovska I ${ }^{1}$, Jakimovska $\mathrm{M}^{1}$, Kubelka-Sabit $\mathrm{K}^{2}$, Karadjozov $\mathrm{M}^{2}$,
} Arsovski A ${ }^{3}$, Stojanovska L ${ }^{3}$, Plaseska-Karanfilska $\mathrm{D}^{1, *}$

\begin{abstract}
*Corresponding Author: Dijana Plaseska-Karanfilska, M.D., Ph.D., Research Centre for Genetic Engineering and Biotechnology "Geogi D. Efremov," Macedonian Academy of Sciences and Arts, Skopje, Republic of Macedonia. Tel: +389-2-3235-410. Fax: +389-2-3155-434. E-mail: dijana@manu.edu.mk
\end{abstract}

\begin{abstract}
Clinical importance of the most common CHEK2 (IVS2+1 G>A, 1100delC, I157T and del5395) and $N B N(\mathrm{R} 215 \mathrm{~W}$ and $657 \mathrm{del} 5)$ gene mutations for breast cancer development in Macedonian breast cancer patients is unknown. We performed a case-control study including 300 Macedonian breast cancer patients and 283 Macedonian healthy controls. Genotyping was done using a fast and highly accurate single-nucleotide primer extension method for the detection of five mutations in a single reaction. The detection of the del5395 was performed using an allele-specific duplex polymerase chain reaction (PCR) assay. We have found that mutations were more frequent in breast cancer patients $(n=13,4.3 \%)$ than in controls $(n=5,1.8 \%)$, although without statistical significance. Twelve patients were heterozygous for one of the analyzed mutations, while one patient had two mutations (NBN R215W and CHEK2 I157T). The most frequent variant was I157T, found in 10 patients and four controls $(p=0.176)$ and was found to be associated with familial breast cancer $(p=0.041)$. CHEK2 1100delC and NBN 657del5 were each found in one patient and not in the control group. CHEK2 IVS2+1G $>$ A and del5395 were not found in our co-
\end{abstract}

\footnotetext{
${ }^{1}$ Research Centre for Genetic Engineering and Biotechnology "Georgi D. Efremov," Macedonian Academy of Sciences and Arts, Skopje, Republic of Macedonia

2 "Adzibadem-Sistina" Hospital, Skopje, Republic of Macedonia

3 "Re-Medika" Hospital, Skopje, Republic of Macedonia
}

hort. Frequencies of the studied mutations are low and they are not likely to represent alleles of clinical importance in the Macedonian population.

Keywords: Breast cancer; $C H E K 2$; Macedonian population; Mutations; $N B N$

\section{INTRODUCTION}

Mutations in the $B R C A 1$ and $B R C A 2$ genes account for around $16.0-25.0 \%$ of high-risk familial breast cancers. Therefore, $75.0-84.0 \%$ of high-risk malignancies are not explained in terms of their genetic determinants. Part of the breast cancer cases could be attributed to genes that have moderate penetrance conferring $6.0-10.0 \%$ risk of developing the disease by the age of 60 , compared with $3.0 \%$ for the general population [1]. Some of these genes encode for proteins that act in concert with each other in the intracellular DNA damage signaling and repair pathways. The CHEK2 and $N B N$ genes belong to this group, and a few years ago were proposed to be attractive candidates for susceptibility genes for breast cancer development.

The CHEK2 gene is located on chromosome 22q12.1 and encodes a G2 checkpoint kinase that plays a critical role in response to DNA damage by phosphorylating tumor suppressor proteins, including p53, Cdc25C, Cdc25A and BRCA1 [2]. The CHEK2 genetic variation in inherited cancer susceptibility was first indicated by Bell et al. [3] in 1999 who discovered CHEK2 1100delC (c.1100delC) germline mutation in patients with Li-Fraumeni syndrome. Ac- 
cording to the meta-analysis provided by the CHEK2 Breast Cancer Case-Control Consortium, 1100delC is the most common CHEK2 mutation conferring a two-fold increase in risk for breast cancer and 10fold increase for breast cancer in males. In addition, heterozygotes for the 1100delC allele have a six-fold elevated risk for bilateral breast cancer development $[4,5]$. There are conflicting results regarding the other rare CHEK2 mutations and their contribution to breast cancer susceptibility. The splice site mutation IVS2 $+1 \mathrm{G}>\mathrm{A}(\mathrm{c} .444+1 \mathrm{G}>\mathrm{A})$ results in a severely truncated CHEK2 protein lacking kinase activity, confers a three-fold risk for breast cancer. The mutation was observed to be associated with an increased risk for breast cancer in the Polish population [6], and has also been detected in the German $[7,8]$ and Byelorussian populations as well [7]. Furthermore, a large CHEK2 deletion spanning exons 9 and 10 (del5395) has been described as a Czech founder mutation [9] and was also found in Poland [10]. The I157T (c.470T $>$ C) missense variant, located within the FHA domain, have previously been reported to be pro oncogenic due to the protein inability to bind to downstream targets including BRCA1, Cdc25A, and p53. The frequency of the I157T variant varies between populations and the highest frequency was observed in Slavic populations. It confers around a 1.5-fold risk for breast cancer, but it is unclear whether it is sufficient to recommend testing in clinical practice [11].

The NBN (NBS1) gene is located on the $8 \mathrm{q} 21.3$ chromosome and encodes a protein that is a component of the MRE11/RAD50/NBN (MRN) complex involved in DNA double-strand break repair, telomere maintenance, and cell-cycle checkpoint control. Biallelic mutations in $N B N$ are responsible for the majority of patients with Nijmegen breakage syndrome (NBS), a radiation sensitivity disorder characterized by microcephaly, growth retardation, immunodeficiency and a marked susceptibility to cancer [12]. Approximately $90.0 \%$ of NBS patients carry the homozygous mutation 657del5 (c.657_661delACAAA) in exon 6 , which has been predominantly identified in Slavic populations and confers a three-fold risk for breast cancer development [13]. Association studies of $N B N$ missense alterations in breast cancer series have not generally supported the hypothesis that amino acid substitutions could contribute to breast cancer susceptibility. However, the R215W (c.643C $>\mathrm{T}$ ) substitution, is proposed to represent a cancer susceptibility allele with low penetrance in breast cancer, conferring around a two-fold risk for breast cancer development in carriers [14].

There are very limited data on the distribution and clinical relevance of $C H E K 2$ and $N B N$ mutations in the Balkan countries. We here report the clinical relevance of the most common mutations in CHEK2 and $N B N$ genes for breast cancer development in Macedonian breast cancer patients. To the best of our knowledge, this is the first study to explore CHEK2 and $N B N$ mutations in a large Balkan cohort.

\section{MATERIALS AND METHODS}

Study Participants. The study population consisted of 300 unselected breast cancer patients. Median age at diagnosis was 50 years, and $30.0 \%$ of patients reported a first degree family history of breast cancer. The patient series had been used previously to determine the frequency of 11 selected mutations in BRCAland BRCA2 genes [15]. The general population controls included 283 female volunteers. Informed written consent was obtained from each participant. The study was approved by the Ethics Committee of the Macedonian Academy of Sciences and Arts, Skopje, Republic of Macedonia. Genomic DNA was isolated from peripheral EDTA blood samples following standard phenol-chloroform extraction procedures.

Genotyping. Polymerase chain reaction (PCR) primers were designed to give a variety of PCR fragment sizes for multiplex PCR (Table 1). The PCR multiplexes were performed in a final volume of 25 $\mu \mathrm{L}$, in $1 \times \mathrm{B} 2$ reaction buffer, $200 \mathrm{mM}$ dinucleotide triphosphate, $2.5 \mathrm{mM} \mathrm{MgCl}_{2}, 10$ pmol of each primer, 1 unit of HOT FIRE Pol DNA polymerase (Solis BioDyne, Tartu, Estonia) and $100 \mathrm{ng}$ of genomic DNA. Thirty-three cycles of PCR amplification were performed with denaturation at $95^{\circ} \mathrm{C}$, annealing at $58^{\circ} \mathrm{C}$ and extension at $72{ }^{\circ} \mathrm{C}$. An aliquot of the completed reaction was treated with Exonuclease I and Shrimp Alkaline Phosphatase (ExoSAP-IT) (Affymetrix, Santa Clara, CA, USA) to eliminate unincorporated nucleotide triphosphates and excess PCR primers overnight at $37^{\circ} \mathrm{C}$, followed by $15 \mathrm{~min}$. at $85^{\circ} \mathrm{C}$ to inactivate the enzyme. The purified PCR products were directly used as templates in a primer extension reaction containing the mutation specific primer mixture (Table 1). The mini sequencing primers were 
Table 1. Primers for multiplex PCR and Single-nucleotide primer extension assay.

\begin{tabular}{|c|c|c|c|c|c|}
\hline Gene & Mutation & & Primer ID & Sequence $\left(5^{\prime}>3^{\prime}\right)$ & $\begin{array}{c}\text { PCR/SnaPshot Size } \\
\text { (bp) }\end{array}$ \\
\hline CHEK2 & $\mathrm{I} 157 \mathrm{~T}$ & $\mathrm{~T} / \mathrm{C}$ & $\begin{array}{l}\text { PCR (F) } \\
\text { PCR (R) } \\
\text { SnaPshot (F) }\end{array}$ & $\begin{array}{l}\text { TTT CGG ATT TTC AGG GTA GG } \\
\text { ATT CAA AGG ACG GCG TTT TC } \\
\text { (4)CAG TGG GTC CTAAAA ACT CTT ACA }\end{array}$ & 241 \\
\hline CHEK2 & IVS2+1G $>$ A & $\mathrm{G} / \mathrm{A}$ & $\begin{array}{l}\text { PCR (F) } \\
\text { PCR (R) } \\
\text { SnaPshot (F) }\end{array}$ & $\begin{array}{l}\text { CTA CTG GTT TGG GAG GGA CA } \\
\text { 5GA CCA AAT TAC CAG CTC TCC } \\
\text { (10)CCA AGA AAC ACT TTC GGA TTT TCA GG }\end{array}$ & $\begin{array}{l}156 \\
35\end{array}$ \\
\hline CHEK2 & c.1100delC & $\mathrm{C} / \mathrm{T}$ & $\begin{array}{l}\text { PCR }(F) \\
\text { PCR (R) } \\
\text { SnaPshot (F) }\end{array}$ & $\begin{array}{l}\text { GCA AAA TTA AAT GTC CTA ACT TGC } \\
\text { CCA GTC TGT GCA GCA ATG AA } \\
\text { (13)CTC CCT TTT GTA CTG AAT TTT AGA TTA }\end{array}$ & $\begin{array}{l}374 \\
39\end{array}$ \\
\hline$N B N$ & $\begin{array}{l}\mathrm{R} 215 \mathrm{~W} \\
657 \mathrm{del} 5\end{array}$ & $\begin{array}{l}\mathrm{C} / \mathrm{T} \\
\mathrm{C} / \mathrm{G}\end{array}$ & $\begin{array}{l}\text { PCR (F) } \\
\text { PCR (R) } \\
\text { SnaPshot (F) } \\
\text { SnaPshot (R) }\end{array}$ & $\begin{array}{l}\text { TGT CAG ATA GTC ACT CCG TTT ACA A } \\
\text { ACC TGT TTG GCA TTC AAA AAT } \\
\text { (20)CAA GTA AAA ATG TTG ATC TGT CAG GA } \\
\text { (28)CAT ATA AAT GTT TTC CCT TTG AAG ATT T }\end{array}$ & $\begin{array}{l}200 \\
45 \\
54\end{array}$ \\
\hline
\end{tabular}

ID: identification; PCR: polymerase chain reaction; F: forward; R: reverse.

5 '-tailed with poly-C sequences of various sizes to produce extension products of 27-54 nucleotides to allow for separation by capillary electrophoresis. For the extension reaction, we used the ABI PRISM ${ }^{\mathrm{TM}}$ SNaPshot Multiplex Kit (Life Technologies, Carlsbad, CA, USA) following the manufacturer's instructions. The extension products were treated with Shrimp Alkaline Phosphatase (Affymetrix). An aliquot of the SAP-inactivated single-nucleotide extension reaction was diluted in $12 \mu 1 \mathrm{HiDi}$ Formamide (Life Technologies), supplied with GeneScan 120 LIZ Size Standard (Life Technologies), heat-denatured, snap-cooled on ice and loaded onto an ABI PRISM ${ }^{\mathrm{TM}} 3010$ Genetic Analyzer (Life Technologies). Extension products were visualized and called automatically using GeneScan 4.0 (Life Technologies).

Detection of the 5395 bp deletion spanning exons 9 and 10 of CHEK2 was performed using an allelespecific duplex PCR assay [10]. Briefly, two primer pairs were used specifically for detection of the large deletion in a single PCR. The first pair flanked the breakpoint site in intron 8 , while the second flanked the breakpoint site in intron 10 . The PCR products were analyzed by agarose gel electrophoresis. $\mathrm{Mu}-$ tation-negative cases produced two PCR fragments of 379 and $522 \mathrm{bp}$ from the wild-type allele, while in the presence of the mutation, the forward primer of the first pair and the reverse primer of the second pair amplified a $450 \mathrm{bp}$ long PCR product.

Statistical Analyses. Fisher's exact test (http:// vassar stats.net/) was used to determine the significant difference in the mutation frequencies between the two groups. Associations with a $p$ value lower than 0.05 were considered to be significant.

\section{RESULTS}

We analyzed 300 patient and 283 control individuals for the presence of $1100 \mathrm{delC}$, IVS $2+1 \mathrm{G}>\mathrm{A}$, I157T, del 5395 in CHEK2 and 657del5, R215W mutations in $N B N$ to determine their frequencies in the Macedonian population. The results are summarized in Table 2. Our primer extension design provides a very fast and highly accurate one-tube

Table 2. Distribution of $C H E K 2$ and $N B N$ analyzed mutation.

\begin{tabular}{|l|c|c|c|c|c|c|c|}
\hline & & \multicolumn{4}{|c|}{ CHEK2 } & \multicolumn{2}{c|}{ NBN } \\
\hline & $\boldsymbol{n}$ & $\mathbf{I 1 5 7 T}$ & IVS2+1G>A & $\mathbf{1 1 0 0 d e l C}$ & $\mathbf{d e l 5 3 9 5}$ & R215W & $\mathbf{6 5 7 d e l 5}$ \\
\hline Unselected patients & 300 & $10(3.33 \%)$ & $0(0.0 \%)$ & $1(0.30 \%)$ & $0(0.0 \%$ & $1(0.30 \%)$ & $1(0.30 \%)$ \\
\hline Controls & 283 & $4(1.41 \%)$ & $0(0.0 \%)$ & $0(0.0 \%)$ & $0(0.0 \%)$ & $1(0.35 \%)$ & $0(0.0 \%)$ \\
\hline$p$ Value & & 0.176 & - & - & - & - & - \\
\hline
\end{tabular}


screening method for detection of five mutations in a single reaction (Figure 1). The identified mutations were validated by Sanger sequencing using BigDye chemistry. The 5395 bp deletion in CHEK2 was assayed by PCR.

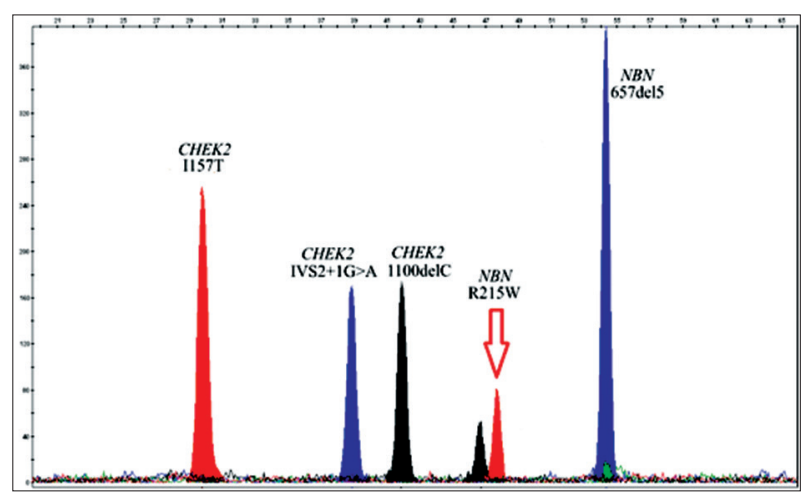

Figure 1. Representative electropherogram from a patient heterozygous for the $\mathrm{R} 215 \mathrm{~W}$ mutation in $N B N$ gene.

The truncation mutation $1100 \mathrm{delC}$ in CHEK2 was detected in one patient $(0.3 \%)$ and in none of the control cohort. The patient was a 31-year-old woman diagnosed with invasive third stage ductal carcinoma, with positive lymph nodes (pN1a), but no metastases. Her mother was diagnosed with breast cancer at age 40 and died 2 years later. The IVS $2+1 \mathrm{G}>\mathrm{A}$ and the $5395 \mathrm{bp}$ deletion were not observed in our analyzed groups. The I157T missense mutation was the most frequent variant identified in our study. It was detected in 10 patients (3.33\%) and four controls $(1.4 \%)$. Statistically significant association was not observed $[p=0.176$, odds ratio $(\mathrm{OR})=1.91 ; 95 \%$ confidence interval (CI): 0.64 to 5.68), although there was a significant association when familial $v s$. non familial breast cancer patients ( $p=0.041, \mathrm{OR}=3.91$; 95\% CI: 0.99 to 15.44$)$ were compared. All patient carriers were of Macedonian descent, median age at first diagnosis was 53 years and all had ductal carcinoma.

The $N B N$ 657del5 mutation was identified in one patient $(0.3 \%)$ and in none of the controls. The patient was a 42-year-old woman diagnosed with invasive ductal carcinoma reporting no relatives diagnosed with breast cancer. The $\mathrm{R} 215 \mathrm{~W}$ mutation was observed in one patient $(0.3 \%)$ and one control individual $(0.35 \%)$. It was interesting to note that the patient carried both the R215W and I157T mutations. She was diagnosed with invasive ductal carcinoma at the age of 43, stage IA and was negative for lymph node and metastasis. She reported a family history of breast cancer from her mother's and father's side of the family. Her mother was diagnosed with breast cancer at the age of 54 and her mother's cousin at age 39, who died 2 years later. Both of her father's sisters had been diagnosed with breast cancer at ages 50 and 62 , and they died a few years after.

\section{DISCUSSION}

There is no universal consensus regarding the importance of CHEK2 and NBN mutations in breast cancer development. Our study was aimed to contribute to the knowledge of their role in breast cancer development in patients from Southern Europe by providing the first data for this geographic region. Surprisingly, we found very low frequencies of the selected mutations in the Macedonian population, which were not in agreement with some previously published data on Slavic populations.

Although it is very rare, the 1100 delC mutation in CHEK2 is the most studied, showing wide variation in the frequency in different populations. Highest frequencies of this mutations in breast cancer patients have been found in The Netherlands (2.9 in patients vs. $1.6 \%$ in controls) [16], Finland (2.0 vs. 1.0\%) [4], and lower in Sweden (1.3 vs. 0.6\%) [17], Denmark (1.2 vs. 0.5\%) [18], USA (1.1 vs. 0.4\%) [19], Germany $(0.8 v s .0 .5 \%)$ [20], Poland (0.5 vs. 0.2\%) [10] and Czech Republic (0.4 vs. 0.3\%) [21].We observed only one $1100 \mathrm{delC}$ mutation carrier, thus showing that the clinical importance of the mutation for the Macedonian population is minor. It was unexpected that we did not detect the IVS2 $+1 \mathrm{G}>$ A mutation and the 5395 bp deletion in our cohort. Though our results are partially in agreement with the data from a small study of 57 HBOC (high grade breast and ovarian cancer) cases in Serbia, where 1100delC was not observed, and only one $5395 \mathrm{bp}$ deletion carrier was identified [22]. IVS2+1G $>$ A was identified as a Polish founder mutation with a frequency of $0.3 \%$ in the general population and $1.2 \%$ in breast cancer patients [6]. It was also observed in German (0.0-0.4\%) [7,8] and Byelorussian populations (0.2\%) [7]. The 5395 del was reported as a founder mutation in Poland with $0.4 \%$ population frequency [10]. Bogdanova et al. [23] found IVS2+1G>A in Byelorussian (0.9\%) and in German breast cancer patients $(0.5 \%)$. 
The studies indicating the relevance of the I157T missense mutation in elevating the risk of developing breast cancer disagreed: either showing an increased risk for breast cancer [7,24-26] or no association with the disease [8,27]. I157T was observed with the highest frequency in two separate studies in Poland (9.3 in breast cancer cases $v s .5 .8 \%$ in controls and $7.6 v s$. $5.1 \%)[24,25]$, Poland and Belarus together (5.5 vs. $3.4 \%$ ) [26], Belarus (5.6 vs. 1.3\%) [7]. Less frequent and without any clinical significance, the variant was observed in Germany (1.9 vs. 1.6\%) [8] and Czech Republic (2.8 vs. 2.5\%) [27]. In our studied population, I157T was twice as frequent in the patient group (3.0 vs. 1.4\%), although statistical significance was not reached $(p=0.176)$. When familial $v s$. non familial breast cancer history patients were compared, the variant was found to be associated with familial breast cancer $(p=0.041)$.

The 657del5 germline mutation in $N B N$ accounts for more than $90.0 \%$ of all mutant alleles in the gene. The highest frequency of heterozygous carriers was found in the Slavic population from Central Europe with an average frequency of 1/177 [13]. Gorski et al. [28] found $657 \mathrm{del} 5$ in $0.8 \%$ of studied breast cancer cases and in $0.6 \%$ of the controls in Poland. Similarly, Steffen et al. [29] found the mutation in 1.96\% unselected breast cancer patients in central Poland and $0.62 \%$ in controls. Bogdanova et al. performed large-scale analysis of breast cancerpatients and controls fromBelarus and Northern Germany. They confirmed that $657 \mathrm{del} 5$ was clearly associated with an increased breast cancer risk in both populations, Belorussian $(0.9 \%$ in patients vs. $0.1 \%$ in controls) and German $(0.1 \%$ in patients and $0 \%$ in controls) [14]. The R215W mutation was once considered a polymorphism of $N B N$, and its severe pathogenicity only emerged with the identification of compound heterozygous 657 del5/R215W NBS patients. Still there are conflicting opinions whether it does represent a cancer susceptibility allele. Bogdanova et al. [14] observed that the R215W substitution may be an allele with lower penetrance for breast cancer development in Northern Germany ( 0.8 in patients vs. $0.2 \%$ in controls), but not in Belorussia (0.6 in patients $v s .0 .5 \%$ in controls). We did not confirm that 657del5 and R215W represent breast cancer risk alleles and our results are in agreement with the results published by Carlomagno et al. [30] and Mateju et al. [31]. Carlomagno et al. [30] performed a large study in the German population and found one 657 del5 mutation in 477 patients $(0.21 \%)$ and one in 866 controls $(0.12 \%)$. In addition, Mateju et al. [31] identified two carriers of the $657 \mathrm{del} 5$ mutation in 703 analyzed cases $(0.28 \%)$ and two in 913 controls $(0.22 \%)$, while they found $\mathrm{R} 215 \mathrm{~W}$ in three patients $(0.43 \%)$ and four controls $(0.44 \%)$ in a Czech cohort. In conclusion, the frequencies of the $N B N$ 657del5 and $\mathrm{R} 215 \mathrm{~W}$ mutations in the Macedonian population are low, and no association of these mutations with breast cancer susceptibility was demonstrated.

In summary, we have analyzed the impact of the most common mutations in CHEK2 and $N B N$ genes on breast cancer development in Macedonian breast cancer patients. We showed that the frequencies of the studied mutations are very low and they do not seem to represent alleles of high clinical importance in our population. Our study is the first to explore CHEK2 and $N B N$ mutations in a large Balkan cohort. It would be of great interest to assess the distribution of these mutations in other Balkan countries. We also established one-tube multiplex PCR for screening all five CHEK2 and NBN mutations in one reaction, which can be used as a fast screening method in populations where these mutations are more common and with clinical relevance.

Declaration of Interest. This study was supported by the Macedonian Academy of Sciences and Arts, Skopje, Macedonia. IMK designed the experiments, performed the analysis and wrote the manuscript; MJ participated in performing the analysis. KKS, MK, AA and LS were involved in recruitment of participants and obtaining informed consent from them. DPK conceived and designed the study. The authors report no conflicts of interest. The authors alone are responsible for the content and writing of this article.

\section{REFERENCES}

1. Stratton MR, Rahman N. The emerging landscape of breast cancer susceptibility. Nat Genet. 2008; 40(1): 17-22.

2. Nevanlinna H, Bartek J. The CHEK2 gene and inherited breast cancer susceptibility. Oncogene. 2006; 25(43): 5912-5919.

3. Bell DW, Varley JM, Szydlo TE, Kang DH, Wahrer DC, Shannon KE, et al. Heterozygous 
germ line hCHK2 mutations in Li-Fraumeni syndrome. Science. 1999; 286(5449): 2528-2531.

4. Vahteristo P, Bartkova J, Eerola H, Syrjakoski K, Ojala S, Kilpivaara O, et al. A CHEK2 genetic variant contributing to a substantial fraction of familial breast cancer. Am J Hum Genet. 2002; 71(2): 432-438.

5. Broeks A, de Witte L, Nooijen A, Huseinovic A, Klijn JG, van Leeuwen FE, et al. Excess risk for contralateral breast cancer in CHEK2*1100delC germline mutation carriers. Breast Cancer Res Treat. 2004; 83(1): 91-93.

6. Cybulski C, Huzarski T, Gorski B, Masojc B, Mier-zejewski M, Debniak T, et al. A novel founder CHEK2 mutation is associated with increased prostate cancer risk. Cancer Res. 2004; 64(8): 2677-2679.

7. Bogdanova N, Enssen-Dubrowinskaja N, Feshchenko S, Lazjuk GI, Rogov YI, Dammann $\mathrm{O}$, et al. Association of two mutations in the CHEK2 gene with breast cancer. Int J Cancer. 2005; 116(2): 263-266.

8. Dufault MR, Betz B, Wappenschmidt B, Hofmann W, Bandick K, Golla A, et al. Limited relevance of the CHEK2 gene in hereditary breast cancer. Int J Cancer. 2004; 110(3): 320-325.

9. Walsh T, Casadei S, Coats KH, Swisher E, Stray $\mathrm{SM}$, Higgins $\mathrm{J}$, et al. Spectrum of mutations in BRCA1, BRCA2, CHEK2, and TP53 in families at high risk of breast cancer. JAMA. 2006; 295(12): 1379-1388.

10. Cybulski C, Wokołorczyk D, Huzarski T, Byrski $\mathrm{T}$, Gronwald J, Górski B, et al. A deletion in CHEK2 of 5,395 bp predisposes to breast cancer in Poland. Breast Cancer Res Treat. 2007; 102(1): 119-122.

11. Liu C, Wang Y, Wang QS, Wang YJ. The CHEK2 I157T variant and breast cancer susceptibility: A systematic review and meta-analysis. Asian Pac J Cancer Prev. 2012; 13(4): 1355-1360.

12. Varon R, Vissinga $C$, Platzer $M$, Cerosaletti KM, Chrzanowska KH, Saar K, et al. Nibrin, a novel DNA double-strand break repair protein, is mutated in Nijmegen breakage syndrome. Cell. 1998; 93(3): 467-476.

13. Varon R, Seemanova E, Chrzanowska K, Hnateyko O, Piekutowska-Abramczuk D, Krajew-
ska-Walasek $\mathrm{M}$, et al. Clinical ascertainment of Nijmegen breakage syndrome (NBS) and prevalence of the major mutation, 657de15, in three Slav populations. Eur J Hum Genet. 2000; 8(11): 900-902.

14. Bogdanova N, Feshchenko S, Schurmann P, Waltes R, Wieland B, Hillemanns $\mathrm{P}$, et al. Nijmegen breakage syndrome mutations and risk of breast cancer. Int J Cancer. 2008; 122(4): 802-806.

15. Maleva I, Madjunkova S, Bozhinovski G, Smickova E, Kondov G, Spiroski Z, et al. Genetic variation of the brca1 and brca2 genes in Macedonian patients. Balkan J Med Genet. 2012; 15(Suppl): 81-85.

16. de Jong MM, van der Graaf WTA, Nolte IM, Te Meerman GJ, Oosterwijk JC, van der Steege G, et al. Increased CHEK2 1100delC genotype frequency (also) in unselected breast cancer patients (conference abstract). American Society of Clinical Oncology Annual Meeting Proceedings (PostMeeting Edition), New Orleans, LA, USA, June 5-8 2004. J Clin Oncol. 2004; 22(14S): 9536.

17. Einarsdottir K, Humphreys K, Bonnard C, Palmgren J, Iles MM, Sjolander A, et al. Linkage disequilibrium mapping of CHEK2: Common variation and breast cancer risk. PLoS Med. 2006; 3(6): e168. doi: 10.1371/ journal. pmed.0030168.

18. Weischer M, Bojesen SE, Tybjaerg-Hansen A, Axelsson CK, Nordestgaard BG. Increased risk of breast cancer associated with CHEK2*1100delC. J Clin Oncol. 2007; 25(1): 57-63.

19. Mateus Pereira LH, Sigurdson AJ, Doody MM, Pineda MA, Alexander BH, Greene MH, et al. CHEK2: 1100delC and female breast cancer in the United States. Int J Cancer. 2004; 112(3): 541-543.

20. Rashid MU, Jakubowska A, Justenhoven C, Harth V, Pesch B, Baisch C, et al. German populations with infrequent CHEK2*1100delC and minor associations with early-onset and familial breast cancer. Eur J Cancer. 2005; 41(18): 2896-2903.

21. Kleibl Z, Novotny J, Bezdickova D, Malik R, Klei-blova P, Foretova L, et al. The CHEK2 c.1100delC germline mutation rarely contributes to breast cancer development in the Czech Republic. Breast Cancer Res Treat. 2005; 90(2): 165-167. 
22. Krivokuca A, Dobricic J, Brankovic-Magic M. CHEK2 1100delC and Del5395bp mutations in BRCA-negative individuals from Serbian hereditary breast and ovarian cancer families. J BUON. 2013; 18(3): 594-600.

23. Bogdanova N, Feshchenko S, Cybulski C, Dork T. CHEK2 mutation and hereditary breast cancer. J Clin Oncol. 2007; 25(19): e26. doi: 10.1200/ JCO.2007.11.4223.

24. Domagala P, Wokolorczyk D, Cybulski C, Huzarski T, Lubinski J, Domagala W. Different CHEK2 germline mutations are associated with distinct immunophenotypic molecular subtypes of breast cancer. Breast Cancer Res Treat. 2012; 132(3): 937-945.

25. Cybulski C, Gorski B, Huzarski T, Byrski T, Gronwald J, Debniak T, et al. Effect of CHEK2 missense variant I157T on the risk of breast cancer in carriers of other CHEK2 or BRCA1 mutations. J Med Genet. 2009; 46(2):.132-135.

26. Serrano-Fernandez P, Debniak T, Gorski B, Bogdanova N, Dork T, Cybulski C, et al. Synergistic interaction of variants in CHEK2 and BRCA2 on breast cancer risk. Breast Cancer Res Treat. 2009; 117(1): 161-165.

27. Kleibl Z, Havranek O, Hlavata I, Novotny J, Sevcik J, Pohlreich P, et al. The CHEK2 gene I157T mutation and other alterations in its prox- imity increase the risk of sporadic colorectal cancer in the Czech population. Eur J Cancer. 2009; 45(4): 618-624.

28. Gorski B, Cybulski C, Huzarski T, Byrski T, Gronwald J, Jakubowska A, et al. Breast cancer predisposing alleles in Poland. Breast Cancer Res Treat. 2005; 92(1): 19-24.

29. Steffen J, Nowakowska D, Niwinska A, Czapczak D, Kluska A, Piatkowska M, et al. Germline mutations 657 del5 of the NBS1 gene contribute significantly to the incidence of breast cancer in Central Poland. Int J Cancer. 2006; 119(2): 472-475.

30. Carlomagno F, Chang-Claude J, Dunning AM, Ponder BA. Determination of the frequency of the common 657Del5 Nijmegen breakage syndrome mutation in the German population: No association with risk of breast cancer. Genes Chromosomes Cancer. 1999; 25(4): 393-395.

31. Mateju M, Kleiblova P, Kleibl Z, Janatova M, Soukupova J, Ticha I, et al. Germline mutations 657del5 and 643C $>$ T (R215W) in NBN are not likely to be associated with increased risk of breast cancer in Czech women. Breast Cancer Res Treat. 2012; 133(2): 809-811. 
